\title{
Sociological Analysis of Absence of Rights and Interests of Mobile Population and Crimes
}

\author{
Yun Han \\ School of Social Work of China Youth University for Political Sciences \\ Beijing 100086, China \\ Tel: 86-10-8856-7627_E-mail: misshan1969@sohu.com, hanyun@cyu.edu.cn
}

\begin{abstract}
Safeguarding rights and interests of mobile population and preventing crimes committed by mobile population can not do without urban development, governmental administration, improvement in and implementation of laws and regulations and supervision and support from social forces. But in practice, the rights and interests of mobile population are often neglected during urban development, local governments face conflicting objectives, interests and responsibilities when coming down to mobile population, the laws and regulations can not be effectively enforced, and there is no effective supervision and support from social forces. To safeguard rights and interests of mobile population and prevent crimes committed by mobile population, the governments at all levels should be people oriented, adopt a scientific outlook on development and create sound interactions among the four subsystems.
\end{abstract}

Keywords: Mobile population, Rights and interests and crimes, External environment

China has experienced great changes in the past 30 years since reform and opening up and is being transformed to a modern country. A good many social problems in current China are associated with this transformation which is called by sociologists as "deconstruction of traditional society and reorganization of modern society". This social transformation results in frequent population flow and huge mobile population in cities. The mobile population has grown from 70 millions in 1993 to 140 millions in 2003, more than 10\% of the total population. Despite of its large size, the principal part of mobile population is rural farmers, which is a vital feature of the social transformation period in China. The mobile population with farmers as the principal part is believed to be a disadvantaged group living at urban fringes as their righteous rights and interests are often infringed. Lawful rights and interests of mobile population, such as political participation, labor employment, social insurance, inhabitation, spare-time culture and children education, can't be safeguarded and even their physical and mental health can't be guaranteed. Under this social background, the crime rate of mobile population is rising and more serious crimes are being committed, which threats China's harmonious and stable society. In this paper, the author tries to make functional analysis of the external environment leading to the absence of rights and interests of mobile population and the crimes they commit, and make preliminary sociological survey of the relations among city management, acts of government, laws and regulations and social forces with an AGIL model.

\section{Research on causes to absence of rights and interests of mobile population and crimes}

Many experts and scholars analyze why rights and interests of mobile population are infringed on and why mobile population commit crimes by considering social factors and mobile population factors. As to social factors, the dualistic urban-rural structure and restrictive household-registration system lead to unequal social status and mental imbalance of mobile population; in China's labor market, the supply exceeds demand and farmers in the mobile population has no power to safeguard their rights; the defective legal system can't safeguard rights and interests of mobile population; the administrative system does not work efficiently and the administrative law enforcement officials from such sector as labor inspection, public security, urban management and business administration often look down upon mobile population, deny justice, enforce law in a slack manner or abstain from an act when the rights and interests of mobile population are infringed. In such a case, the mobile population sometimes strives against administrative enforcement of law or safeguards their rights and interests in unlawful means; the social security and rescue system is deficient and there is a lack of support from government and social organizations. As to mobile population, most of them are rural 
farmers who have poor education background, lack their own organizations and are indifferent to safeguarding rights according to law. When coming across injustice and unfairness or when their rights and interests are infringed, they may resort to illegal or wrongful means if they can't get social support and help.

In my opinion, most of mobile population are rural farmers, safeguarding their rights and interests can't be separated from preventing their crimes, and the principal cause to crimes of mobile population is that their lawful rights and interests can't be safeguarded and they have no way to turn to. From this point of view, if rights, benefits and freedom of mobile population are safeguarded, crimes of mobile population would be reduced greatly, therefore, local governments should give priority to safeguarding lawful rights and interests of mobile population instead of simply taking them to shelters or dismissing them or placing undue emphasis on the fall of crime rate. In this sense, the external environment for safeguarding rights and interests of mobile population should be mainly analyzed as it has a close relation with the crime rate of mobile population.

\section{Functional analysis based on AGIL Model}

It is seen from above views that this social movement safeguarding rights and interests of mobile population and preventing crimes of them develops and functions in a specific environment or a special system, thus the effect depends on the external environment, namely whether different parts of the environment or principal parts of the movement could cooperate and interact with each other, which could be interpreted with the functional analysis method of Parsons. According to Parsons, a functional body can give play to its functions and maintain coordination and stability of the whole only through meeting four demands. The four demands are: A) environmental adaptation, G), objective acquisition from environment, I) system integration, and L) functional mode maintenance. The external environment safeguarding rights and interests of mobile population and preventing crimes of them can also be a functional body, and its sound operation and development can't get away from the effective operation, inter-coordination and progress of the four subsystems. This functional body does not start with macroscopic social structure and system or microscopic individuals, but studies problems in an external environment with multi-relations.

In this functional body, the primary mission of A) city is to provide means of production and services, pursue urban development and prosperity and ensure internal solidarity, stability and sound city operation. Urban development is the precondition for existence of mobile population and urban development and mobile population are in mutual dependence and interaction. Properly handling their relationship could boost urban development and guarantee social stability, thus urban development is to adapt to the environment of safeguarding rights and interests of mobile population and preventing crimes. The responsibilities of G) government is to establish policies, laws and regulations, exercise labor administration and act as arbiter in order to normalize the behaviors of employing units, prevent them from infringing upon the lawful rights and interests of mobile population and create a favorable environment for social development. Therefore the government is the decision maker and executor for attaining the goal of safeguarding rights and interests of mobile population and preventing their crimes. I) laws and regulations, as the most authoritative social control means, could be used to coordinate group relations, safeguard the interests of each party and promote integration of social forces, but the effective implementation of laws and regulations depend on whether they are in reason, whether they are executed fairly and whether the public understand them. L) Social forces include development of social morality and support from social organizations. Development of social morality refers to encouraging people to abide by social behavior standards through their internal belief and social public opinions, and could be used to create the social ethical environment for safeguarding rights and interests of mobile population and preventing crimes of them. Social organizations include NGOs and trade unions for providing social support to safeguard rights and interests of mobile population and providing sustained supervision mechanism.

\subsection{Current problems}

To safeguard rights and interests of mobile population, the above four subsystems need to function normally. To maintain a system for safeguarding rights and interests of mobile population and preventing crimes of them, the functional requirement of the four parts needs to be satisfied, namely city management and development should adapt to the environment for safeguarding rights and interests of mobile population, local governments will guarantee the attainment of goals of safeguarding rights and interests of mobile population, laws and regulations would integrate social groups and forces and social forces supports and maintains this functional body. What is more important is that the four subsystems should be coordinated smoothly and maintain harmonious and stable relations in order to boost the healthy development of the functional body. But in practice, the four subsystems are often disconnected, for instance, the government does not supervise urban development and enterprise employee management; laws and regulations are defective and not well enforced by government; there is a lack of social morality and good faith at enterprises; and it is not strongly supported by public opinions. This is the reason why lawful rights and interests of mobile population can't be safeguarded and why mobile population crime rate is on the rise. Through AGIL functional model, what we would analyze is the external environment where rights and interests of mobile population are lost and the disconnected relationship. 


\section{Opportunism during urban and enterprise development and absence of government}

In the system safeguarding rights and interests of mobile population and preventing crimes of them, cities and enterprises shoulder direct and principal responsibilities, while the reality is that cities and enterprises have opportunistic tendency, as mobile population is in face of strict identification and status restriction as well as discrimination and unfair treatment from urban society. The majority of mobile population is expelled to a "secondary labor market" different from urban population, where the supply exceeds the demand in the long term (a typical buyer's market). This is in connection with the opportunism during urban development, cities hope to maximum interests at lower cost, and the cheap labor force of mobile population correspond directly with this objective. Therefore, cities hope to get adequate mobile population as labor force while they are reluctant to change the poor status of mobile population in order to keep the "buyer's market" in the long run. In the "buyer's market", mobile population is in a disadvantaged position and their rights and interests are likely to be infringed. Enterprises also tend to maximize their profits at the minimum cost, thus they also have the opportunism tendency just like cities. As compared with enterprises, mobile population is a weak group and it is more difficult to have their rights and interests safeguarded. At the present time, the biggest problem is that the infringement upon rights and interests of mobile population by enterprises is not strictly treated, which further encourages the opportunism of enterprises.

When their rights and interests are infringed, the mobile population is contradictory as to whether they should take measures to safeguard their rights. As the mobile population has no special organization and hopes to keep their jobs and basic source of income, thus they may not resort to crimes if the infringement act of cities and enterprises can be accepted. In reality, the crime rate of mobile population is on the rise, showing the absence of government besides opportunism of cities and enterprises.

The government is the executor of the objective of safeguarding rights and interests of mobile population and preventing crimes of them and government works directly affect the realization of this objective. In recent years, the central government has formulated a series of policies on mobile population, urging local governments at all levels and related functional departments to safeguard rights and interests of mobile population. But the unequal domiciliary register system is still kept, the dualistic urban-rural structure has not been changed fundamentally and no compulsory education and social security are provided to mobile population yet. In fact, the central government has transferred the task and responsibility of safeguarding rights and interests of mobile population to local governments and has not made substantial adjustment at central level, and the national treatment of mobile population is still not given. Moreover, the country has not provided effective social security and support to mobile population, thus mobile population can only resort to themselves when their rights and interests are violated. Without correct guidance, mobile population tends to safeguard their rights and interests in illegal and improper means and may even commit crimes.

In reality, although local governments at all levels have adopted measure to implement central policies and expanded the scope of participating departments (from labor security departments at the beginning to civil administration departments, public security sectors, building departments, financial sectors and judicial departments) and right-safeguarding scope. But it is clear that the government has not undertaken the role as arbiter and justice keeper, or the government is inefficient in safeguarding rights and interests of mobile population.

The interests of local governments are connected with urban and enterprise development, and the opportunism of urban and enterprise development would surely affect the formulation and execution of governmental policies. There is conflict between interests of local governments and rights and interests of mobile population. Professor Sun Liping from Sociology Department of Tsinghua University thought that the governmental snobbism would influence social justice. Local governments are in the same boat as cities and enterprises and they give priority to economy and enterprise development. To improve fiscal revenue and attract investment with favorable investment environment, local governments hope to maximum interests with less fiscal expenditure and they share common interests with some enterprises and do not hesitate to sacrifice lawful rights and interests of mobile population. This makes it come to a deadlock to safeguard the rights and interests of mobile population, damage the credit of governments and leads to crimes of mobile population when their rights and interests are infringed as they have no way to turn to.

\section{Ineffective laws and regulations}

It is unlikely to depend on the government to safeguard lawful rights and interests of mobile population, and it is laws and regulations that should guarantee the rights and interests of mobile population fundamentally. But related laws and regulations are invalid in fact. On one hand, related legal system and judicial mechanism are defective; on the other hand, the authority of laws and regulations is counteracted by the self-interest of local governments in the process of enforcement. When laws and regulations and executed, local governments, influenced by opportunism and utilitarianism during urban and enterprise development, impair the social integration function of laws and regulations. Therefore, in practice, laws and regulations can't be executed by local governments effectively.

The current legal system and judicial mechanism safeguarding rights and interests of mobile population are defective in 
some aspects. First, mobile population is not well protected. With respect to enterprises, mobile population is in inferior position and related laws of labor are not appropriately directed to mobile population. Moreover, the most of mobile population is working at small and medium-sized enterprises and privately-run enterprises and business owners often replace written labor contracts with oral agreements in order to reduce production cost. In this way, the lawful rights and interests of mobile population can't be protected by law when they are infringed. Second, laws and regulations are not operable. It is specified in the Labor Law that the resolution of labor disputes is arbitration first and then litigation, which is challenging for mobile population, because it is costly and inefficient, so when their rights and interests are infringed, they tend to solve problems by themselves, or even commit crimes in some cases. Third, the judicial mechanism is defective. Mobile population is not well supervised and inspected owing to lack of technology, equipment and personnel, thus infringement upon rights and interests of mobile population can't be discovered and solved in time and mobile population crimes can't be prevented effectively. Upon disputes between mobile population and enterprises, juridical authorities often can't produce evidences or powerful evidences as juridical authorities has restricted ability of taking evidences and cross-examining evidences owing to the low education level of mobile population and as some enterprises refuse to provide original data or only provide evidences favorable to them.

Safeguarding rights and interests of mobile population and preventing crimes of them requires improving laws and regulations as well as judicial mechanism and requires interaction and influence of related legal factors, especially interaction between laws and regulations and local governments and urban enterprises. In a sense, laws and regulations function through such interactions and they would be invalid if such relationship is broken.

As mentioned above, some local governments, influenced by utilitarianism and opportunism during urban and enterprise development, place undue emphasis on economic indicators and don't hesitate to sacrifice the lawful rights and interests of mobile population in order to create a favorable investment environment and gain higher fiscal revenue and better achievement. The result is that the rights and interests of mobile population are not safeguarded and mobile population has no way to turn to when their rights and interests are infringed. Moreover, some enterprises share certain interests with local governments, thus local governments do not care the infringement of rights and interests of mobile population by business owners. "Local authorities select investment environment, and press and deprive labors of rights and interests". In such a case, laws and regulations become ineffective and can't be implemented in deed.

Therefore, laws and regulations alone are far from enough and they are nothing without social environment and interactive relationship for effective implementation. To follow out laws and regulations, restoring their authority and justice in the mind of local governments, urban enterprises and mobile population is the key for safeguarding rights and interests of mobile population and preventing crimes of them.

\section{Inefficient supervision and support by social morality and social organizations}

Social forces play an important role for safeguarding rights and interests of mobile population. The modern enterprises that absorb mobile population as labor force should, in accordance with the requirement of modern vocational ethics, standardize the system of personnel placement, safeguard lawful rights and interests of mobile population and ensure their legitimate interests. In particular, the enterprises that directly employ mobile population to take hard or dangerous jobs must actively sign labor contracts and insurance contracts with mobile population for safeguarding their rights and interests and fulfill their responsibilities as contracted. As a modern enterprise, safeguarding lawful rights and interests of mobile population is to undertake social responsibilities and practice social morality. But in reality, some enterprises, influenced by opportunism and utilitarianism, infringe upon rights and interests of mobile population to lower labor cost and pursue profits by making use of weak points of mobile population, such as lack of rights-safeguarding awareness and poor organization. They ignore lawful rights and interests and physical and mental health of mobile population and thus lack social morality and unprejudiced socialist market spirit.

Most of Mobile population is from relatively backward rural districts with dense traditional colors, and they know little about employment system and contract system in modern cities and enterprises, and they are unfamiliar with market rules, laws and regulations and do not know how to safeguard lawful rights and interests in the labor relationship. In particular, the loopholes of the system safeguarding rights and interests of mobile population deprive mobile population of voice right, thus no timely and effective solution could be provided when the rights and interests of mobile population are infringed. In the face of business owners lacking social morality and consciousness, mobile population feels powerless and can't seek external help. In such a case, mobile population is likely to commit crimes to safeguard their own rights and interests.

Social morality means safeguarding lawful rights and interests of mobile population from ideological level, namely people's belief and their moral level, and the goal is to create a social environment where mobile population is well treated. Public opinions and public supervision are direct and effective approach to check whether social morality could attain its goal. In reality, we could also witness this force, for instance, since 1990's, investigators and media at home and abroad have been continuously disclosing the infringement on lawful rights and interests of labors at some export processing plants in Pearl River Delta and they pointed out that transnational companies should be to blame. Such 
public opinions led to resistance against some well-known brands, forcing some transnational corporations to make response and to push ahead with social responsibility inspection, labor contract system and production manual implementation in plant.

Besides social morality and public opinions, the function of social organizations can't be ignored. An important reason why the rights and interests of mobile population are infringed is that mobile population is dispersed and not organized for safeguarding rights. Currently, it is quite difficult to establish an organization to safeguard rights of mobile population and existing social organizations also can't play this role. The reasons are as follows: first, mobile population has not urban population identify and is not permitted to establish organizations in cities. Moreover, there is a huge mobile population and it is discriminated by some government agencies, thus it is full of difficulties for mobile population to establish organizations. Second, it is difficult for trade unions to safeguard the rights and interests of mobile population, which deprives mobile population of strong social organization support. In a modern enterprise, the trade union is actually a coordinator and has no substantial power to safeguard the rights and interests of mobile population. It is quite difficult for trade unions to play their role in deed without support of labor inspection and social security departments.

Due to lack of ways to voice and safeguard their rights and interests, mobile population has organized some "associations of fellow provincials or townsmen", "fraternal order", etc. in many cities, which is due to their isolation from urban organizations and aims to meet the demand for safeguarding their own rights and interests. Therefore, the government and society should correctly guide such self-organized organizations instead of regarding them as illegal organizations and suppressing them. Without social morality and proper guidance of social forces, such organizations may commit crimes and become floating criminal organizations when the rights and interests of their members are infringed, which deserves attention of the society and the government.

\section{Conclusion}

Through survey of the external environment safeguarding the rights and interests of mobile population, we are clear about the relations and interactions among the four subsystems in this system of act. For the time being, this external environment is not optimistic and the four subsystems are disconnected and can't interact with each other smoothly. Of course, safeguarding rights and interests of mobile population depend on both improvement in the external environment and improvement in the quality of mobile population, especially the promotion of rights-safeguarding awareness and organization degree. In this point, local governments should bear responsibilities and stick to the principle of putting people in the first and governing for the people. As to implementation of specific policies and principles, local governments must abide by the principles of openness and fairness, apply executive power in accordance with laws and regulations and adopt proper measures to safeguard lawful rights and interests of mobile population and achieve balanced development of society and economy. Only after the lawful rights and interests of mobile population are reasonably and effectively safeguarded, mobile population can be melted into urban development in deed and crimes of mobile population can be effectively controlled.

\section{References}

Chen, Xiaoyu. (2001). Sociological Thinking about Mobile Population Crimes in Transformation Stage. Journal of Anhui University of Technology (Social Science edition), Review 18, No. 4.

Jiang, Lihua \& Fu Ping. (2006). Analysis of External Environment Where Rights and interests of Rural Migrant Workers are Absent. Study and Practice, Issue 8.

Jiang, Min. (2001). Thoughts on Building Mechanism Guaranteeing Rights and interests of Mobile Population in China. Review 18, No. 2.

Jiang, Min. (2006). Thoughts on Building a Mechanism Guaranteeing Rights and interests of Mobile Population in China. Review 18, No. 2.

Li Meng. (2004). Market Malfunction, Organization Absence and Protection of Rights and interests of Rural Migrant Workers. Socialism Studies, Issue 6.

Liu, Shaojie. (2006). Foreign Sociological Theories, (the first edition). Higher Education Press. P167.

Liu, Xia. (2006). Analysis of Mobile Population Crime Causes and Countermeasures. Journal of Shandong Agricultural Administrators College, Review 22, No. 2.

No time to delay to legislate for China's mobile population above 140 millions. People's Daily, July 27, 2005.

Sun, Liping. (2003). Breaking-Chinese Society since 1990's. Social Sciences Academic Press. P 147-158.

Sun, Liping. Governmental Snobbish would Affect Social Justice. TAOS.

Tan, Shen \& Liu, Kai-ming. (2003). Social Responsibilities of Multinational Companies and Chinese Society. Social Sciences Academic Press, P6-18.

Zheng, Guanghuai. (2005). Wounded and Disabled Rural Migrant Workers: the Deprived Group. Sociological Studies, Issue 3 . 